\title{
Deriving consistent long-term vegetation information from AVHRR reflectance data using a cover-triangle-based framework
}

\author{
Randall J. Donohue a,b,*, Michael L. Roderick ${ }^{\mathrm{b}}$, Tim R. McVicar ${ }^{\mathrm{a}}$ \\ a CSIRO Land and Water and eWater CRC, GPO Box 1666, Canberra ACT 2601, Australia \\ ${ }^{\mathrm{b}}$ Research School of Biological Sciences, Australian National University, GPO Box 475, Canberra ACT 2601, Australia
}

\section{A R T I C L E I N F O}

\section{Article history:}

Received 1 August 2007

Received in revised form 20 December 2007

Accepted 9 February 2008

\section{Keywords:}

Vegetation dynamics

Cover triangle

Soil line

Dark point

AVHRR

Reflectance

NDVI

fPAR

Atmospheric effects

Sensor calibration

\begin{abstract}
A B S T R A C T
Long-term vegetation dynamics associated with climatic changes can be assessed using Advanced Very High Resolution Radiometer (AVHRR) red and near-infrared reflectance data provided that the data have been processed to remove the effects of non-target signal variability, such as atmospheric and sensor calibration effects. Here we present a new method that performs a relative calibration of reflectance data to produce consistent long-term vegetation information. It is based on a simple biological framework that assumes that the position of the vegetation cover triangle is invariant in reflectance space. This assumption is in fact an intrinsic assumption behind the commonly used Normalised Difference Vegetation Index (NDVI) and is violated when the NDVI is calculated from inadequately corrected reflectance data. In this new method, any temporal variability in the position of the cover triangle is removed by geometrically transforming the observed reflectance data such that two features of the triangle-the soil line and the dark point-are stationary in reflectance space. The fraction of Photosynthetically Active Radiation absorbed by vegetation (fPAR; 0.0-0.95) is then calculated, via the NDVI, from calibrated reflectances. This method was tested using two distinct, monthly AVHRR products for Australia: (i) the coarse-resolution, fully calibrated, partially atmospherically corrected PAL data (1981-1994); and (ii) the fine-resolution, fully calibrated, nonatmospherically corrected HRPT data (1992-2004). Results show that, in the 20-month period when the two datasets overlap (1992-1994), the Australia-wide, root mean square difference between the two datasets improved from 0.098 to 0.027 fPAR units. The calibrations have produced two approximately equivalent datasets that can be combined as a single input into time-series analyses. The application of this method is limited to areas that have a wide-enough variety of land-cover types so that the soil line and dark point are evident in the cover triangle in every image of the time-series. Another limitation is that the methodology performs only bulk, relative calibrations and does not remove the absolute effects of observation uncertainties. The simplicity of the method means that the calibration procedure can be easily incorporated into near-real-time operational remote-sensing environments. Vegetation information produced using this invariant-cover-triangle method is expected to be well suited to the analysis of longterm vegetation dynamics and change.
\end{abstract}

(c) 2008 Elsevier Inc. All rights reserved.

\section{Introduction}

Remotely sensed data can be used to measure and monitor vegetation characteristics in high spatial and temporal detail across large areas. Historically, this has been achieved using vegetation indices derived from multi-temporal reflectance of red $(0.6-0.7 \mu \mathrm{m})$ and near-infrared (NIR; 0.7-1.1 $\mu \mathrm{m}$ ) radiation (e.g., Tucker, 1979; Running \& Nemani, 1988; Nemani et al., 2003). Analyses of long-term vegetation dynamics require reflectance data that are not significantly affected by non-target signal variability associated with remotely sensed data (e.g., Gutman, 1999). Traditional methods for correcting reflectance data typically require ancillary data to drive atmospheric

\footnotetext{
* Corresponding author. CSIRO Land and Water and eWater CRC, GPO Box 1666 Canberra ACT 2601, Australia.

E-mail address: Randall.Donohue@csiro.au (R.J. Donohue).
}

or directional reflectance models (e.g., Tanre et al., 1992; Los et al., 2005) or are delayed until publication of post-launch calibration coefficients (e.g., Mitchell, 1999). Across Australia, the application of traditional correction methods to Advanced Very High Resolution Radiometer (AVHRR) data is problematic because ancillary data (especially water vapour and aerosol data) that span both the country and the entire AVHRR observation period are generally unavailable. Additionally, traditional approaches do not lend themselves to realtime operational environments. For these reasons we developed, and present here, a simple, biologically oriented approach to calibrating broad-scale satellite reflectance data, akin to those of Hall et al. (1995) and Pickup et al. (1993), where knowledge of vegetation and soil reflectance characteristics is used to drive the calibration procedure. There are also similarities between this current method and the 'cover triangle' method of Gillies and Carlson (1995; see also Carlson (2007)) which standardises the Normalised Difference Vegetation Index 
(NDVI) and surface temperature values in order to estimate soil moisture. The basis of the method we present here is the assumption that key features of the cover triangle (described in Section 1.2) are spectrally invariant. Using these features, the relative temporal effects of non-target signal variability are minimised in the data, thereby producing consistent vegetation information suitable for long-term time-series analysis. In the remainder of this introduction, we review traditional methods of correcting AVHRR data and then present the rationale for the new calibration approach. Following the introduction, we present and discuss this new calibration methodology using, as a case study, two monthly AVHRR data products spanning continental Australia from June 1981 to December 2004.

\subsection{Traditional approaches to correcting AVHRR reflectance data}

The series of polar-orbiting environmental satellites operated by the National Oceanographic and Atmospheric Administration (NOAA) each carry an AVHRR sensor. These sensors measure spectral radiance using a number of bandwidths including 0.58-0.68 $\mu \mathrm{m}$ (Channel 1) and $0.725-1.1 \mu \mathrm{m}$ (Channel 2) which measure red reflectance $\left(\rho_{\mathrm{R}}\right)$ and NIR reflectance $\left(\rho_{\mathrm{N}}\right)$, respectively. The available AVHRR data record is near-continuous from June 1981 and provides one of the longest useful remotely sensed records of the Earth's surface. For this reason these data are of exceptional value in the analysis of long-term variability in vegetation, especially those relating to land-use change (e.g., Graetz et al., 1995) and climate change (e.g., Nemani et al., 2003). The main obstacle to using AVHRR data in terrestrial applications is the presence of variability in the reflectance signal that originates not from the surface target but from atmospheric dynamics, from timedependent changes in the sensors, and from variations in Sun-targetsensor geometry (Cracknell, 1997). In the absence of adequate corrections for this signal variability, time-series analyses can lead to inaccurate conclusions about vegetation dynamics and especially about long-term vegetation change (Gutman, 1999).

From a vegetation perspective, non-target signal variability constitutes uncertainties in the reflectance data. AVHRR data are susceptible to a variety of uncertainties, each having specific effects on $\rho_{\mathrm{R}}$ and $\rho_{\mathrm{N}}$ and on the resultant Normalised Difference Vegetation Index (NDVI). These uncertainties, shown in Table 1 , can be broadly categorised as atmospheric effects and satellite sensor effects. The most important atmospheric effects originate from the scattering and absorption of radiation by gases and aerosols. Satellite sensor effects are more time dependent, originating from post-launch degradation of sensor calibrations and from changes in Sun-target-sensor geometry, caused, in part, by satellite orbital drift (Kaufman, 1989; Price, 1991).

Traditionally, atmospheric effects are corrected individually using models of atmospheric optical properties. Molecular scattering and ozone absorption effects are generally predictable over space and time and can be corrected for relatively simply (Kaufman, 1989). In contrast, the effects of aerosol scattering and water-vapour absorption are spatially and temporally dynamic and are therefore more difficult to correct for directly (El Saleous et al., 2000). Correction of sensor effects is particularly important prior to long-term time-series analyses of reflectance data as these effects can introduce artificial trends into reflectance data (Price, 1987; Gutman, 1999) as well as alter the magnitude of atmospheric effects (Kaufmann et al., 2000). Both sensor degradation and orbital drift effects are commonly corrected using invariant-target analysis (Che \& Price, 1992; Gordon et al., 1988; Vermote \& Kaufman, 1995; Gutman, 1999; Kaufman \& Holben, 1993; Roderick et al., 1996b). In this type of analysis, dark and bright targets are identified in geographic space whose reflectances are assumed to be constant. Trends in measured reflectance from invariant targets are attributed to sensor effects and are removed from all reflectance data. Invariant-target analysis is retrospective, typically requiring several years of data collection prior to analysis. Illumination effects have been addressed using bidirectional reflectance distribution functions (BRDF) that correct reflectances to a standard Sun-target-sensor angle (e.g., Cihlar et al., 1997; Los et al., 2005; Bacour et al., 2006). However, many BRDF corrections require specification of land-surface parameters and, as these parameters can be highly dynamic, such corrections can be difficult to accomplish reliably over long time-periods and across large areas.

Another commonly used method of minimising atmospheric and sensor effects is Maximum Value Compositing (MVC; Holben, 1986). MVC was originally developed to minimise the effect of clouds on calculated NDVI but it also minimises any effect that reduces the NDVI including aerosol scattering and water-vapour absorption (Holben, 1986). Consequently, MVC preferentially selects measurements made through clear and dry atmospheres with minimum optical depths (Kaufman, 1989). The longer the compositing period the more effective MVC becomes in minimising atmospheric effects (Holben, 1986); indeed, in areas where aerosol and water-vapour effects are not large, even 10 day composites can render these effects insignificant (Kaufman \& Tanre, 1992). Whilst traditional approaches to correcting AVHRR data are effective at removing uncertainties, they can be complex and there can be considerable delay after the remotely sensed data are acquired before full corrections can be implemented. One of the motivations behind the research presented here was to develop a calibration methodology that is effective and simple, and the idea of enforcing a stationary cover triangle holds potential as a means for achieving this.

\subsection{A new approach for calibrating AVHRR reflectance data using the cover triangle}

The vegetation cover triangle was first described by Kauth and Thomas (1976) who demonstrated that $\rho_{\mathrm{R}}$ and $\rho_{\mathrm{N}}$ (\%) from a large geographic area form a characteristic 'tasselled cap', or triangle, when plotted in red-NIR space (Fig. 1). In this triangle, reflectance from bare soils plot linearly along the base of the triangle and form the 'soil line'. $\rho_{\mathrm{R}}$ and $\rho_{\mathrm{N}}$ from bare soils are approximately equal so the soil line generally has a slope $\left(\alpha_{\mathrm{s}}\right)$ close to 1 and an $\rho_{\mathrm{N}}$-intercept $\left(\beta_{\mathrm{s}}\right)$ near the origin (Rondeaux et al., 1996; it should be noted that sensors from

Table 1

The potential influence of atmospheric and sensor effects on $\rho_{\mathrm{R}}, \rho_{\mathrm{N}}$, and the NDVI

\begin{tabular}{|c|c|c|c|c|}
\hline Source of variability & Potential effect on $\rho_{\mathrm{R}}$ & Potential effect on $\rho_{\mathrm{N}}$ & Potential effect on NDVI & Reference \\
\hline Molecular scattering & $+7 \%$ & $+2 \%$ & -0.23 over densely vegetated targets & $\begin{array}{l}\text { Tanre et al. (1992) } \\
\text { El Saleous et al. (2000) }\end{array}$ \\
\hline Ozone absorption & $-15 \%$ & - & +0.06 over sparsely vegetated targets & As above \\
\hline Aerosol scattering & $+15 \%$ & $+8 \%$ & -0.2 over densely vegetated targets & As above \\
\hline Water-vapour absorption & $-5 \%$ & $-30 \%$ & -0.12 over sparsely vegetated targets & As above \\
\hline Sensor calibration degradation & \multirow{2}{*}{\multicolumn{2}{|c|}{$\begin{array}{l}\text { Effect is satellite-dependent but generally decreases } \\
\rho_{\mathrm{R}} \text { and } \rho_{\mathrm{N}} \text { reflectance } \\
\text { Effect depends on the pre-processing (e.g., length of } \\
\text { MVC period, accuracy of atmospheric corrections) } \\
\text { and sensor calibration accuracy, and is of significance } \\
\text { mainly over sparsely vegetated surfaces }\end{array}$}} & Varies between satellites & $\begin{array}{l}\text { Kaufman (1989) } \\
\text { Price (1987) }\end{array}$ \\
\hline Illumination angle due to orbital drift & & & & $\begin{array}{l}\text { Kaufmann et al. (2000) } \\
\text { Bacour et al. (2006) } \\
\text { Mitchell (1999) }\end{array}$ \\
\hline
\end{tabular}




\section{a}

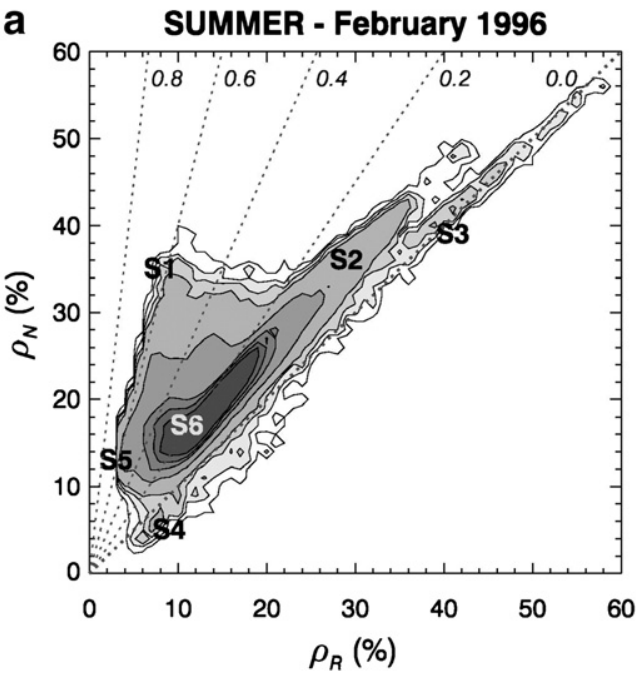

C

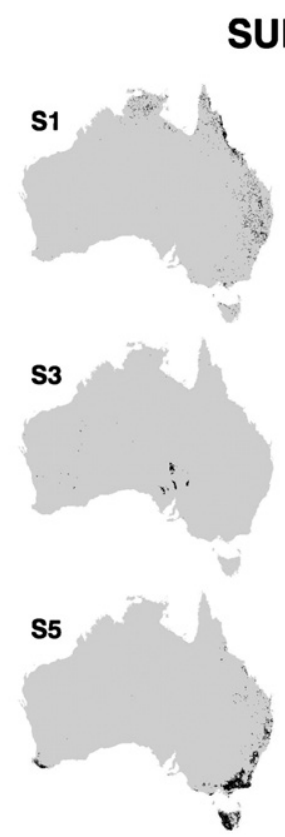

b

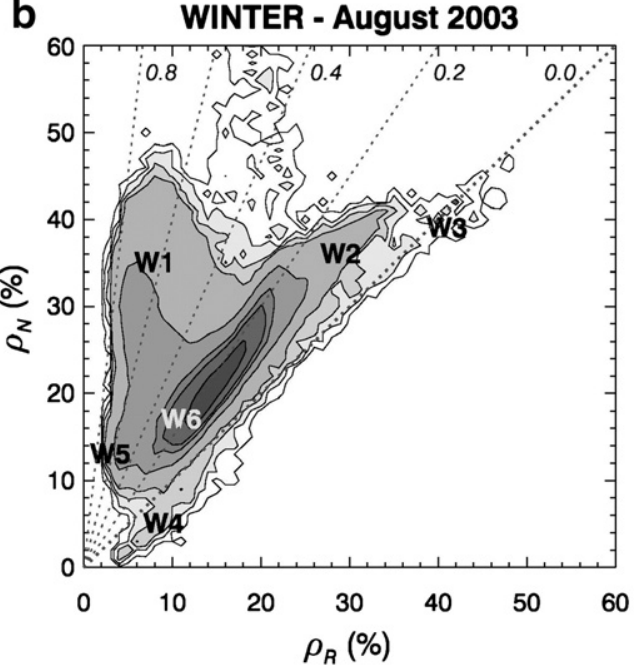

d

WINTER

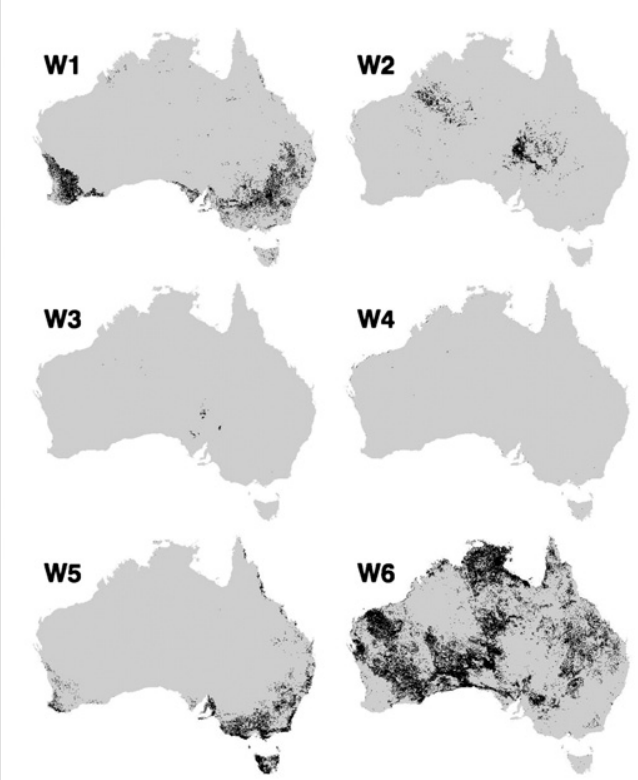

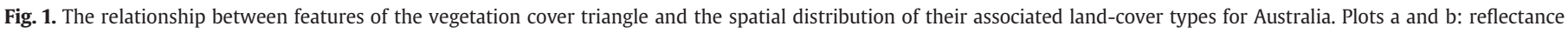

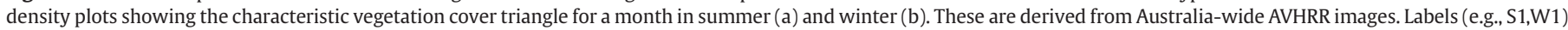

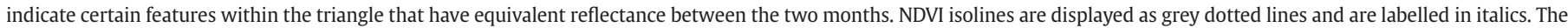

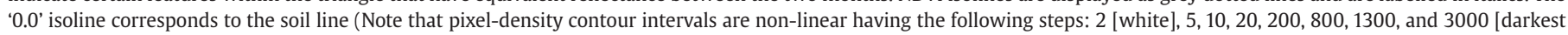

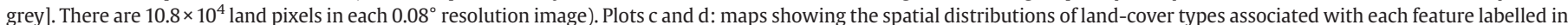

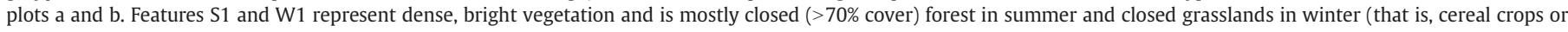

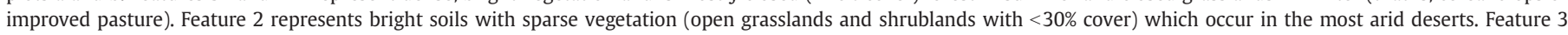

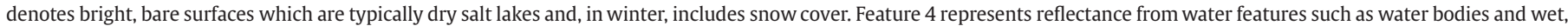

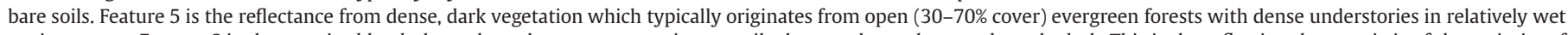

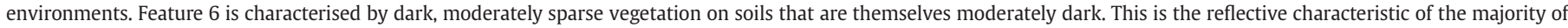
Australia's land cover, which typically consists of woodlands ( $<30 \%$ cover), shrublands, or grasslands (the last two both having $<70 \%$ cover).

across different satellite programmes measure different red and NIR bandwidths resulting in variations in the soil-line position between sensors (Galvao et al., 1999)). Vegetation has a unique spectral signature as $\rho_{R}$ from green foliage is small compared to $\rho_{N}$, with the difference between the two becoming more marked as vegetation cover increases (Huete, 1988, Oke, 1987). Reflectance from vegetated surfaces plots some distance above the soil line, with this distance increasing as canopy cover increases (Graetz \& Gentle, 1982, Walker et al., 1986). The vegetation cover triangle is the data space bounded by the soil line and the reflectance from the densest canopies ('dense' is used throughout this article in reference to cover such that dense vegetation is at or near full cover and has the highest NDVI values; Fig.
1). In contrast, the reflectance from water and bare, wet surfaces plots below the dark end of the soil line (Fig. 1). This is because of the low albedo of water generally and because water absorbs proportionally more $\rho_{\mathrm{N}}$ than it does $\rho_{\mathrm{R}}$ (Oke, 1987; Richardson \& Wiegand, 1977).

Red- and near-infrared-based vegetation indices are designed to capture various characteristics of the cover triangle, particularly the location of the soil line and the differences in $\rho_{\mathrm{R}}$ and $\rho_{\mathrm{N}}$. The most commonly used vegetation index is the NDVI (Rouse et al., 1974), defined as:

$\mathrm{NDVI}=\frac{\rho_{\mathrm{N}}-\rho_{\mathrm{R}}}{\rho_{\mathrm{N}}+\rho_{\mathrm{R}}}$ 
This index is based on the assumption that $\alpha_{\mathrm{s}}$ is $1, \beta_{\mathrm{s}}$ is 0 , and that vegetation isolines converge at the origin (see Fig. 1). The NDVI is not a biophysical parameter and has no absolute range of values. Conversely, it is closely related to fractional green cover (0-1; Carlson \& Ripley, 1997; Lu et al., 2003) and to the fraction of Photosynthetically Active Radiation absorbed by vegetation (fPAR, 0-0.95; Asrar et al., 1984). It has been used to make inferences about vegetation characteristics such as Leaf Area Index (e.g., McVicar et al., 1996; Pierce et al., 1993), canopy structure (e.g., Berry \& Roderick, 2002), phenology (e.g., DeFries et al., 1995; Jolly et al., 2005; Guerschman et al., 2003), biomass (e.g., Baret et al., 1989), and vegetation type (e.g., Hill et al., 1999). The NDVI has also been related to vegetation-related phenomena-for example, landscape condition (Boer \& Puigdefabregas, 2003; Holm et al., 2003); drought severity (McVicar \& Jupp, 1998); biodiversity (Gould, 2000); carbon assimilation (Asrar et al., 1984); water availability (Wellens, 1997), and catchment energy and water balances (Szilagyi, 2000; Donohue et al., 2007a).

For time-series analyses using the NDVI, it is crucial that the position of the cover triangle-and the soil line in particular-be correctly located through time so that any detected changes in index values only relate to true changes in vegetation characteristics. Properly calibrated reflectance data should display no variability in the cover-triangle position. Several vegetation indices (e.g., SAVI and TSAVI) have been developed which allow the characteristics of the soil line, the index isolines, or both, to be individually specified (Huete, 1988; Baret \& Guyot, 1991; Pickup et al., 1993; Qi et al., 1994; Yoshioka et al., 2000) and these indices lend themselves to time-series analyses using data that have not been adequately calibrated (e.g., Pickup et al., 1993). The approach behind such indices is to adapt the index structure to suit the characteristics of the reflectance data. The alternative approach presented in this paper is to adjust the reflectance data so the cover-triangle position is temporally fixed in red-NIR space prior to calculating the NDVI.

Invariant-target analysis identifies the combined effect of signal uncertainties and has the advantage that multiple-source uncertainties can be corrected without having to account for each source individually. Another approach to correcting reflectance data, one that is related to invariant-target analysis, is the end-member analysis presented by Hall et al. (1995). Although developed to make absolute corrections to reflectance data for measuring forest structural characteristics, Hall et al. (1995) proposed that the technique could also be used to correct for uncertainties in satellite reflectance data. End-member analysis requires independent measurements of surface targets that are known to uniquely occupy each apex of the cover triangle (the 'end members'). End-member reflectances are then used to correctly locate the entire cover triangle. In the next section we present the new method for calibrating remotely sensed red-NIR data that combines the invariant-target and end-member concepts to enforce a stationary cover triangle. In forcing this, the methodology produces data suitable for long-term time-series analyses of land-surface characteristics by minimising the relative temporal impacts of atmospheric and sensor effects on the resultant biophysical measurements.

\section{Methods and materials}

\subsection{Approach}

Conceptually, the method for calibrating AVHRR reflectance data presented here is an 'invariant-cover-triangle' approach. It utilises two features of the cover triangle: the soil line and the dark point. The latter represents the left-most extremity of the triangle where absorption of red light by vegetation is at a maximum (see Section 2.3.2). Using these two features, we linearly transform the reflectance data so the cover triangle is consistently located through time before calculating the NDVI and fPAR. We assume that, in the absence of atmospheric and sensor effects:

1. the NDVI is an appropriate index to use (i.e., the vegetation isolines converge at the origin);

2. the soil line is stationary and lies along the 1:1 line (i.e., $\alpha_{\mathrm{s}}$ is 1 and $\beta_{\mathrm{s}}$ is 0 ); and

3. the dark point is stationary and is located at $2 \% \rho_{\mathrm{R}}$ (i.e., dense green canopies can absorb a maximum of $98 \%$ of incident red light, see Section 2.3.2).

It is worth noting that this method presumes a global soil line and therefore can only be applied to areas where a wide range of (unvegetated) soil types are encompassed in the imagery.

In this section we describe the AVHRR reflectance data used here as a case study. We then describe the first step in this calibration methodology which has three components: a) identify the position of the observed soil line in red-NIR space; b) identify the position of the observed dark point in red-NIR space; and c) correct the reflectance data to account for the variability in these two features. In the second step, the NDVI is calculated from the corrected reflectances and converted to fPAR. Although it is very similar to the NDVI, we prefer fPAR because it is a biophysical attribute that directly links vegetation with surface energy and water fluxes (Asrar et al., 1984). The results in Section 3 are presented using a similar outline.

\subsection{Data}

Reflectance data from two AVHRR data products were used to construct the longest complete monthly time-series for Australia as practical; that is from July 1981 to current. The two data products are: i) the Pathfinder AVHRR Land (PAL) Global Area Coverage (GAC) data; and ii) the High Resolution Picture Transmission (HRPT) data. Data specifications, including the pre-processing undertaken by NASA (Kidwell, 1998) and CSIRO Marine and Atmospheric Research (King, 2003), are described in Table 2.

In the last 5 months of the PAL record, orbital drift of NOAA11 resulted in high Solar Zenith Angles (SZA). Consequently, data from these months were removed from analyses. Additionally, data for

Table 2

Specifications and pre-processing of the PAL and HRPT reflectance datasets used in this study

\begin{tabular}{|c|c|c|}
\hline Specification & PAL & HRPT \\
\hline Spatial resolution & $0.08^{\circ}$ at nadir $(\sim 8 \mathrm{~km})$ & $0.01^{\circ}$ at nadir $(\sim 1.1 \mathrm{~km})$ \\
\hline $\begin{array}{l}\text { Temporal } \\
\text { resolution }\end{array}$ & 1 month & 1 month \\
\hline Temporal extent & $\begin{array}{l}07 / 1981-04 / 1994, \\
\text { excluding portions } \\
\text { of SE Australia for } \\
05 / 1984-08 / 1984 \text {, } \\
06 / 1988-07 / 1988 \text {, } \\
\text { and } 06 / 1993-07 / 1993\end{array}$ & $\begin{array}{l}04 / 1992-12 / 2004, \\
\text { excluding } 05 / 1993-08 / 1993 \text {, } \\
\text { 05/1994-01/1995, } \\
\text { and 05/2000-08/2000 }\end{array}$ \\
\hline Data-sensor & 07/1981-02/1985 NOAA7 & 04/1992-09/1994 NOAA11 \\
\hline lineage & 03/1985-10/1988 NOAA9 & 02/1995-09/2000 NOAA14 \\
\hline $\begin{array}{l}\text { Compositing } \\
\text { method }\end{array}$ & Maximum NDVI & Maximum NDVI \\
\hline Cloud removal & CLAVR (Stowe et al., 1991) & CLAVR (Stowe et al., 1991) \\
\hline BRDF corrections & None & None \\
\hline $\begin{array}{l}\text { Atmospheric } \\
\text { corrections }\end{array}$ & $\begin{array}{l}\text { Molecular and ozone } \\
\text { (Gordon et al., 1988) }\end{array}$ & None \\
\hline $\begin{array}{l}\text { Post-launch sensor } \\
\text { calibration }\end{array}$ & Rao (1993) & $\begin{array}{l}\text { Calwatch (Mitchell, 1999) } \\
\text { NOAA11-Mitchell (1999) } \\
\text { NOAA14-Vermote and } \\
\text { El Saleous (see Mitchell, 1999) } \\
\text { NOAA16-none applied } \\
\text { (E. King, pers. comm.) }\end{array}$ \\
\hline
\end{tabular}



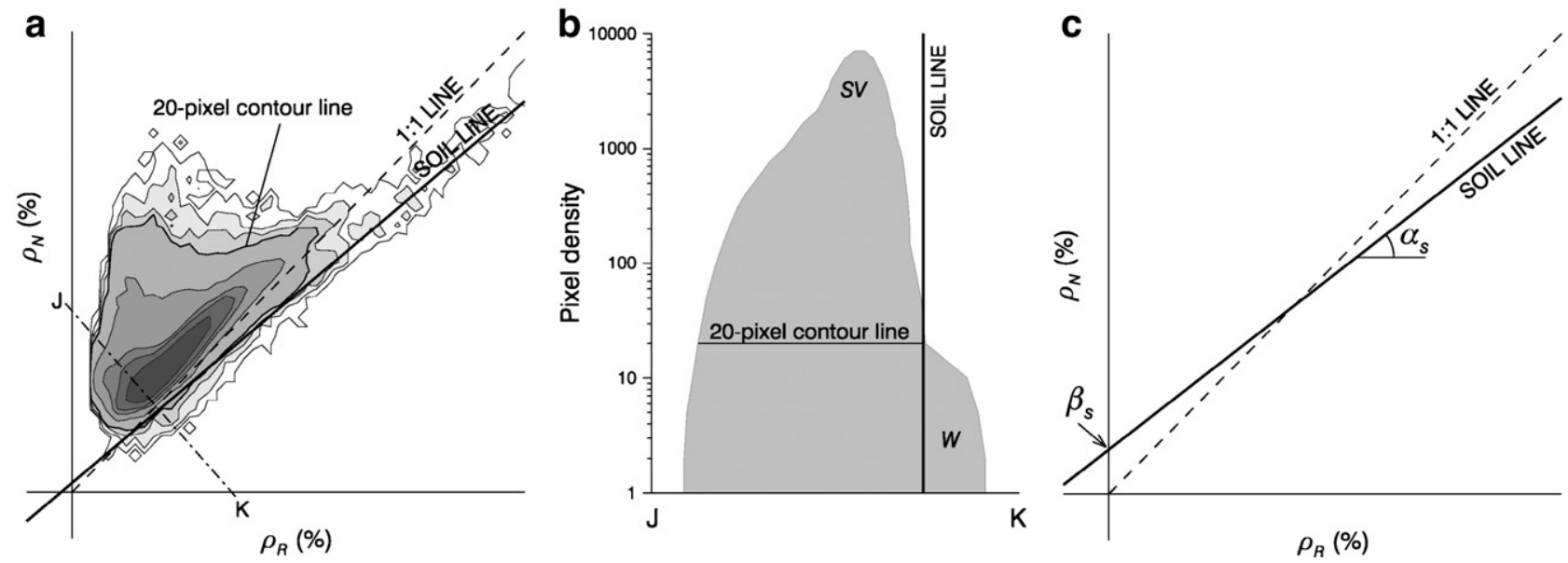

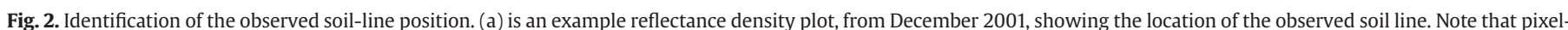

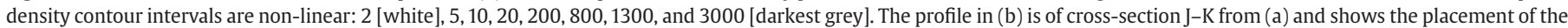

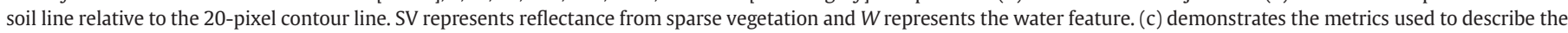
position of the observed soil line, which is described by its slope, $\alpha_{\mathrm{s}}$, and $\rho_{\mathrm{N}}$-intercept, $\beta_{\mathrm{s}}$.

June-August 1984, June-July 1988, and June-July 1993 were of low quality (e.g., areas of saturated reflectance values and/or remnant swathe boundaries) in south-eastern Australia and were masked out (see Donohue et al., 2007b). The original HRPT dataset was missing several months of data (September 1994-January 1995). An additional 14 monthly images (i.e., May-August 1993, April-September 1994, and May-August 2000) were entirely removed from the time-series due to spurious reflectance values in the south of Australia related to high SZA at the end of satellite operational lifespans. Both datasets have had the CLAVR algorithm (Stowe et al., 1991) applied prior to maximum value compositing in order to minimise the effect of clouds on the compositing process. The original reflectance data $\left(\rho_{\mathrm{R}}, \rho_{\mathrm{N}}\right)$ were
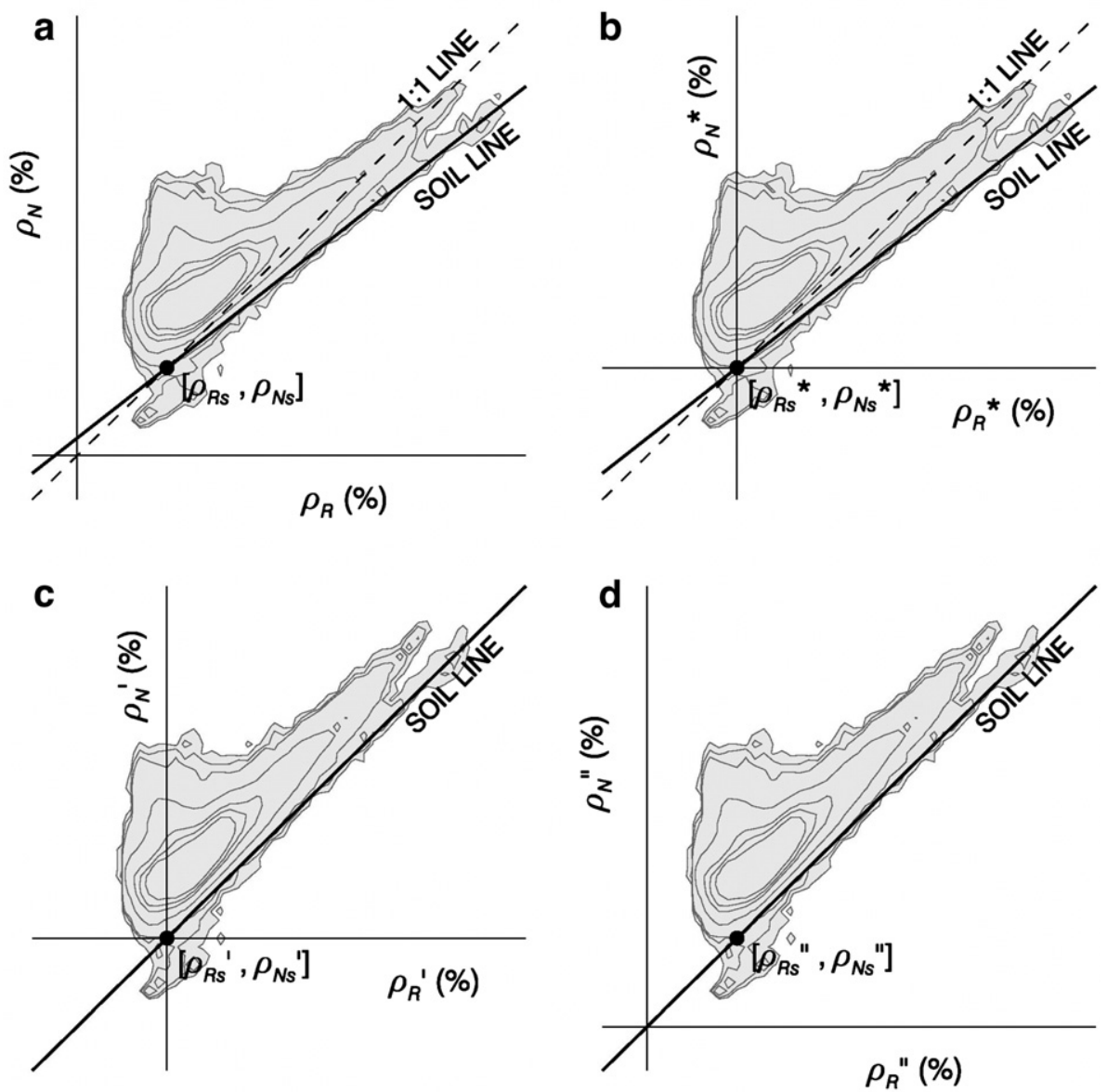

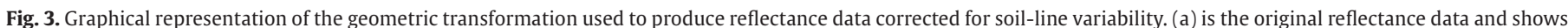

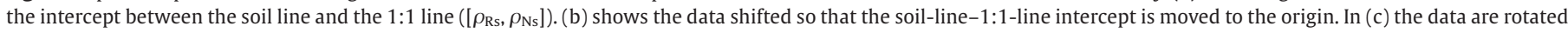

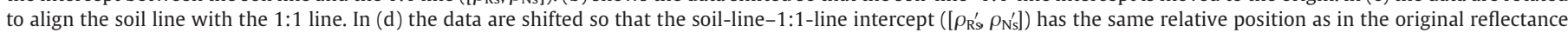
coordinates. 
used to calculate 'original' NDVI values ( $V_{\text {orig }}$ ) for both the PAL and HRPT datasets using Eq. (1).

\subsection{Correcting for soil-line and dark-point variability}

\subsubsection{Identifying the soil line}

To correct for variations in the position of the cover triangle, the position of the soil line must be identified in an objective and repeatable manner. The method used to identify the observed soilline position has three components. Firstly, an Australia-wide redNIR density plot was generated for each month for both PAL and HRPT data (Fig. 2a).

Secondly, two features within each density plot were identified as anchor points for the ends of the observed soil line (Fig. 2a). The bright end of the soil line was anchored using the reflectance from dry salt lakes (e.g., feature 3 in Fig. 1). This feature provides a reliable reference point as it forms an easily identifiable, bare-soil feature quite distinct from other parts of the cover triangle. Surface moisture is known to alter reflectance from salt lakes (Mitchell et al., 1997) and for this reason they are not favoured as invariant geographic features. However, the salt-lake feature in reflectance space is formed by the reflectance from numerous dry salt lakes across Australia and is not affected by changes in surface moisture of any one lake. The dark end of the soil line was anchored using the top side of the water feature (e.g., feature 4 in Fig. 1). Variability in surface moisture causes instability in the shape of the water feature, which forms the lower edge of the cover triangle in the density plots. To avoid this soil-moistureinduced variability, the dark end of the soil line was anchored by aligning it against the 20-pixel contour line immediately above the water feature. This particular contour line was chosen as it is located at the very sharp threshold that delineates the water feature from the reflectance of sparse vegetation on moderately dark soils (Fig. 2b). Therefore this contour's location in this part of the triangle represents the reflectance from dry soils. Application of this method to other regions would require the reassessment of which contour line lies closest this threshold for each particular study area. These two anchoring features were easily identified in the monthly $\rho_{R}-\rho_{N}$ density plots and provided a means for objectively and consistently identifying the soil-line position.

Thirdly and lastly, metrics describing the location of the soil line, now defined as a line that passes through the salt-lake feature and tangent to the 20-pixel contour line, were determined from the $\rho_{\mathrm{R}}-\rho_{\mathrm{N}}$ density plots. These metrics, shown in Fig. 2c, include the soil-line slope $\left(\alpha_{\mathrm{s}}\right)$ and $\rho_{\mathrm{N}}$-intercept $\left(\beta_{\mathrm{s}}\right)$.

\subsubsection{Identifying the dark point}

As for the soil line, correcting for variability in the position of the dark point of the cover triangle required that the location of the observed dark point be identified in a consistent manner. We identify the dark point as the left-most extremity of the cover triangle and describe it simply as a red coordinate (see Fig. 4a).

There is a physical limitation to how much red light can be absorbed by green leaves, which lies between 90 and 95\% (Hume et al., 2002; Jones, 1992). Due to the multiple scattering of light within canopies, vegetation can absorb more red light than individual leaves. We denote the threshold of minimum red reflectance from canopies as $M(\%)$. Kaufman (1989) reported that $\rho_{\mathrm{R}}$ from forest canopies is $1-3 \%$ and from pastures $2-4 \%$ and suggested setting $M$ to $2 \%$; accordingly, we set $M$ to $2 \%$ here.

\subsubsection{Correcting for soil-line and dark-point variability}

To correct for the variability in the cover-triangle position, the original PAL and HRPT reflectance data were geometrically transformed, firstly so that the soil line was aligned with the 1:1 line and, secondly so that the dark point was $2 \% \rho_{\mathrm{R}}$ for every month. This procedure follows the two-dimensional conformal transformation
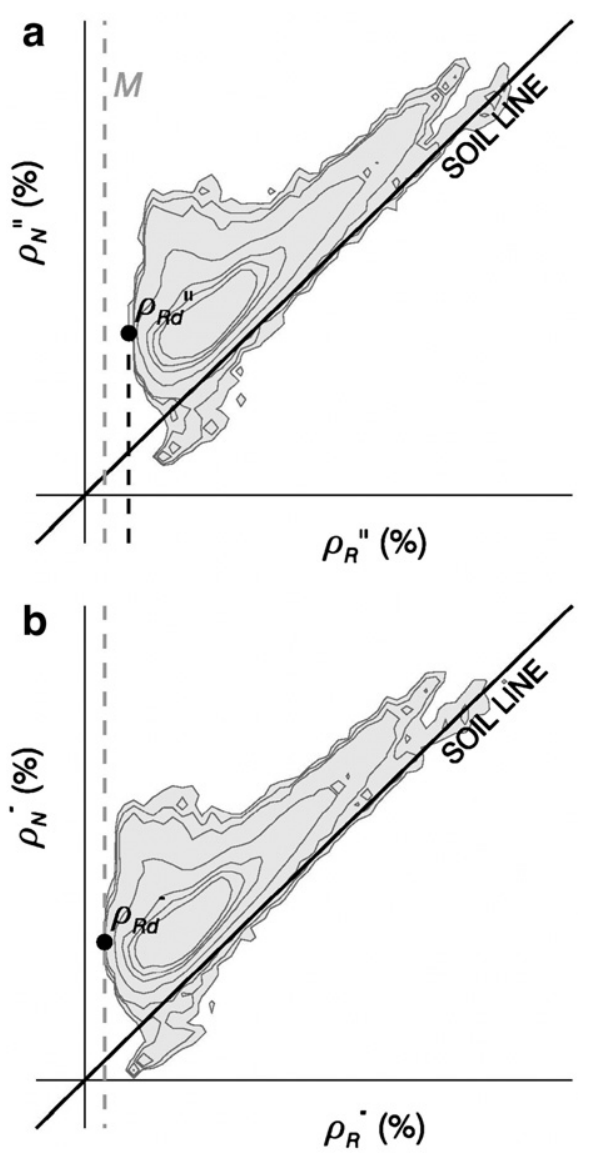

Fig. 4. Graphical representation of the transformation used to produce reflectance data corrected for dark-point variability. In (a) reflectance data corrected for soil-line variability $\left(\rho_{\mathrm{R}}^{\prime \prime}, \rho_{\mathrm{N}}^{\prime \prime}\right)$, showing the location of the dark point $\left(\rho_{\mathrm{Rd}}^{\prime \prime}\right)$ and the minimum red threshold $(M)$. In (b), reflectances are shifted parallel to the soil line so that $\rho_{\mathrm{Rd}}^{\prime \prime}=M$.

described by Wolf (1974), assuming no rescaling was necessary. Using $\alpha_{\mathrm{s}}$, and $\beta_{\mathrm{s}}$, we calculated the intercept between the soil line and the $1: 1$ line $\left(\left[\rho_{\mathrm{Rs}}, \rho_{\mathrm{Ns}}\right]\right.$; Fig. 3a).

The $\rho_{\mathrm{R}}$ and $\rho_{\mathrm{N}}$ data were shifted so that $\left[\rho_{\mathrm{Rs}}, \rho_{\mathrm{Ns}}\right]$ was located over the origin (Fig. 3b):

$\rho_{\mathrm{R}}^{*}=\rho_{\mathrm{R}}-\rho_{\mathrm{Rs}}$

$\rho_{\mathrm{N}}{ }^{*}=\rho_{\mathrm{N}}-\rho_{\mathrm{Ns}}$.

$\rho_{\mathrm{R}}{ }^{*}$ and $\rho_{\mathrm{N}}{ }^{*}$ were rotated to align the soil line with the $1: 1$ line (Fig. 3c):

$\rho_{\mathrm{R}}^{\prime}=\rho_{\mathrm{R}}{ }^{*} \cos (\Theta)-\rho_{\mathrm{N}} * \sin (\Theta)$

$\rho_{\mathrm{N}}^{\prime}=\rho_{\mathrm{R}} * \sin (\Theta)+\rho_{\mathrm{N}} * \cos (\Theta)$

where $\Theta$ is the difference between $45^{\circ}$ and $\alpha_{\mathrm{s}}$, with $\alpha_{\mathrm{s}}$ expressed in degrees. The rotated reflectance data $\left(\rho_{\mathrm{R}}^{\prime}, \rho_{\mathrm{N}}^{\prime}\right)$ were shifted back from the origin so that $\left[\rho_{\mathrm{R} s}^{\prime}, \rho_{\mathrm{N}}^{\prime}\right]$ occupied the same relative position it had in the original reflectances, producing reflectance data adjusted for soil-line variability:

$\rho_{\mathrm{R}}^{\prime \prime}=\rho_{\mathrm{R}}^{\prime}+\rho_{\mathrm{Rs}}$

$\rho_{\mathrm{N}}^{\prime \prime}=\rho_{\mathrm{N}}^{\prime}+\rho_{\mathrm{Ns}}$

Soil-line-adjusted NDVI $\left(V_{\mathrm{adj}}\right)$ was calculated from $\rho_{\mathrm{R}}^{\prime \prime}$ and $\rho_{\mathrm{N}}^{\prime \prime}$. The dark point $\left[\rho_{\mathrm{Rd}}^{\prime \prime}\right]$ was identified as the left-most extremity of the cover triangle plotted using the soil-line-adjusted reflectances (Fig. 4a). Dark-point values were measured to the nearest $1 \%$. The dark point was anchored by shifting both $\rho_{\mathrm{R}}^{\prime \prime}$ and $\rho_{\mathrm{N}}^{\prime \prime}$ so that $\rho_{\mathrm{Rd}}^{\prime \prime}$ was moved to $M$, 
which was set to $2 \%$ (Fig. $4 \mathrm{~d}$ ). This yielded reflectance data corrected for both soil-line and dark-point variability $\left(\rho_{\mathrm{R}}^{-}\right.$and $\left.\rho_{\mathrm{N}}^{-}\right)$:

$\rho_{\mathrm{R}}^{-}=\rho_{\mathrm{R}}^{\prime \prime}+M-\rho_{\mathrm{Rd}}^{\prime \prime}$

$\rho_{\mathrm{N}}^{-}=\rho_{\mathrm{N}}^{\prime \prime}+M-\rho_{\mathrm{Rd}}^{\prime \prime}$.

Note that $\rho_{\mathrm{R}}^{\prime \prime}$ is present in both Eqs. (5a) and (5b) so that the data are shifted along the soil line.

Corrected NDVI $\left(V_{\text {cor }}\right)$ was calculated from $\rho_{\mathrm{R}}^{-}$and $\rho_{\mathrm{N}}$.

\subsection{Conversion of NDVI to fPAR}

A preliminary fPAR $\left(F_{\text {pre }}\right)$ was calculated from the corrected NDVI $\left(V_{\text {cor }}\right)$ by linearly rescaling the NDVI using maximum and minimum thresholds (Roderick et al., 1999):

$F_{\text {pre }}=\frac{\left(F_{x}-F_{n}\right)\left(V_{\text {cor }}-V_{n}\right)}{V_{x}-V_{n}}+F_{n}$.

$F_{x}$ and $F_{n}$ are the maximum and minimum possible fPAR values and were set to 0.95 and 0.0 , respectively. $V_{x}$ and $V_{n}$ are the corresponding maximum and minimum NDVI thresholds, respectively. $V_{x}$ represents complete foliage cover where visible light absorption by canopy foliage is at a maximum and $V_{n}$ represents zero green vegetation cover (e.g., bare soil) where visible light absorption by vegetation is minimal. $F_{\text {pre }}$ was set to 0.95 when $V_{\text {cor }}>V_{x}$, and was set to 0.0 when $V_{\text {cor }}<V_{n}$.

Interim Biogeographic Regionalisation for Australia (IBRA) 5.1 (Environment Australia, 2000) regions were used to determine $V_{x}$ and $V_{n}$. Six IBRA regions with very dense vegetation cover at some time throughout the year and six regions with minimal vegetation cover at some time of the year were chosen, based on a priori knowledge and interrogation of the NDVI database. We ensured that the 'maximum' regions included both native and agricultural vegetation and that the 'minimum' regions included both bright and dark soil backgrounds. A spatially averaged $V_{\text {cor }}$ time-series was created for each maximum and minimum IBRA region. The highest (lowest) $V_{\text {cor }}$ from each maximum (minimum) IBRA time-series was identified and these six values were averaged to produce one $V_{x}\left(V_{n}\right)$ value for all Australia. This was done separately for the PAL and HRPT datasets.

In general, in the 20-month period when the two datasets overlap (Apr 1992-Apr 1993 and Sep 1993-Mar 1994), HRPT F $F_{\text {pre was lower than }}$
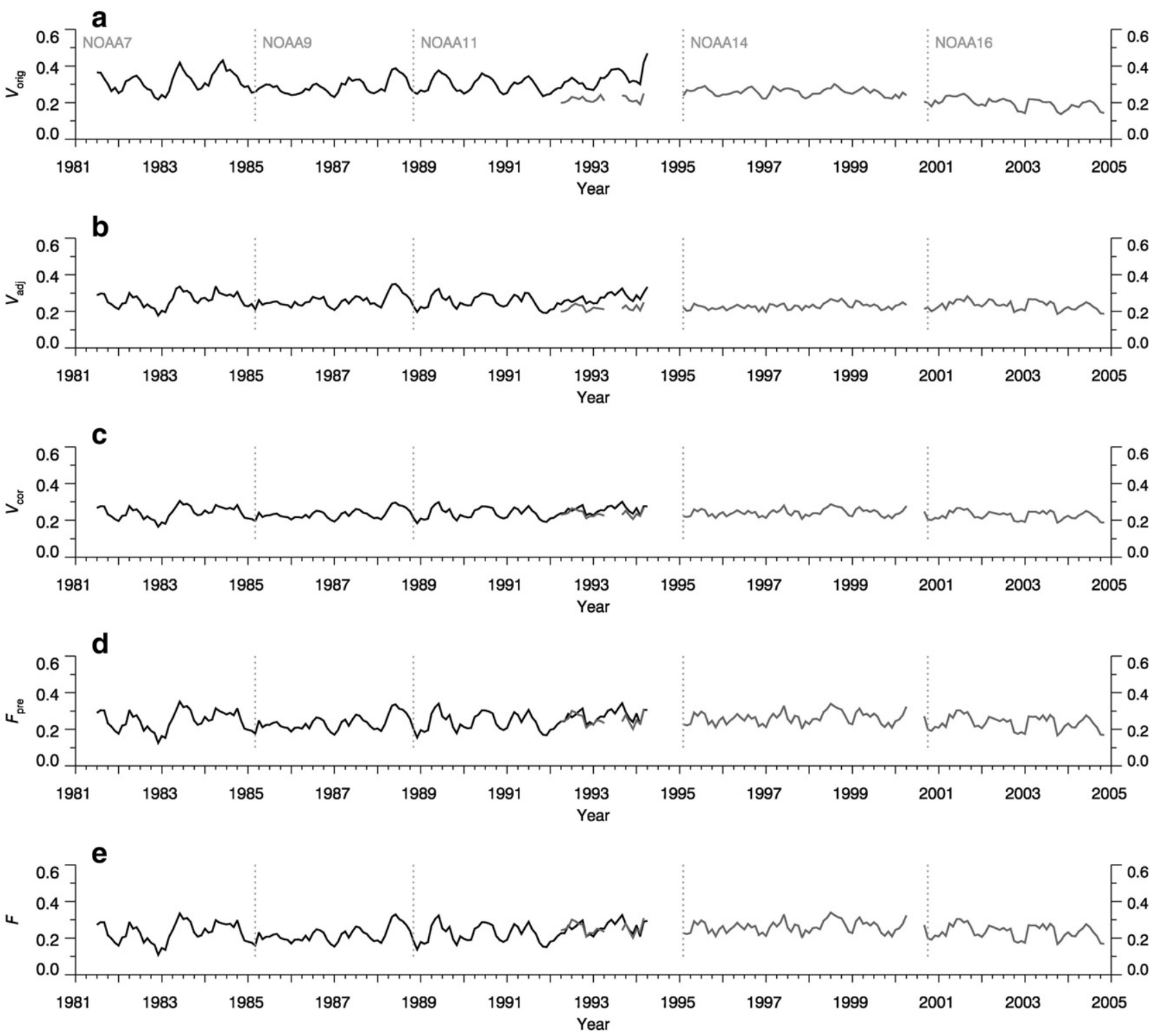

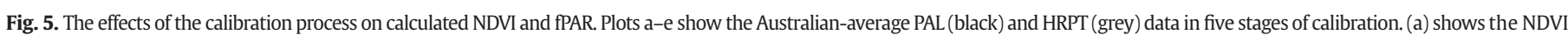

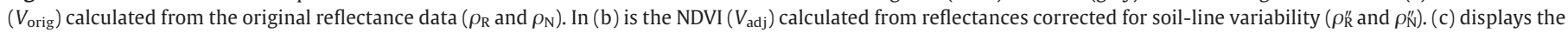

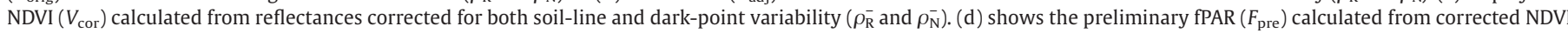

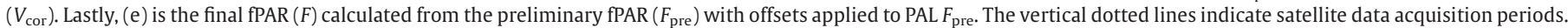


Table 3

Comparison between the original NDVI and the final PPAR derived from the PAL and HRPT datasets

\begin{tabular}{|c|c|c|c|c|}
\hline & \multicolumn{2}{|c|}{ Original NDVI ( $V_{\text {orig }}$ ) } & \multicolumn{2}{|c|}{ Final fPAR $(F)$} \\
\hline & PAL & HRPT & PAL & HRPT \\
\hline Overall mean ${ }^{\mathrm{a}}$ & $0.305[0.290]$ & $0.228[0.217]$ & 0.230 & 0.250 \\
\hline Mean seasonal amplitude ${ }^{a, b}$ & $0.113[0.107]$ & $0.068[0.065]$ & 0.132 & 0.100 \\
\hline $\begin{array}{l}\text { Mean difference in overlap } \\
\text { period }^{c}\end{array}$ & $0.100[0.095]$ & & -0.001 & \\
\hline $\begin{array}{l}\text { Root mean square difference } \\
\text { in overlap period }{ }^{c}\end{array}$ & $0.103[0.098]$ & & 0.027 & \\
\hline
\end{tabular}

As the NDVI and fPAR values used here have slightly different scales (0.0-1.0 and 0.00.95 , respectively), in order to allow direct comparison between these two variables the original NDVI are also presented in fPAR-equivalent units (that is, rescaled by multiplying by 0.95 ); these values are in square brackets.

a Calculated using the entire length of each dataset.

b The seasonal amplitude is the difference between the maximum and minimum value in each calendar year.

c Differences are calculated by subtracting the Australian-average HRPT from the Australian-average PAL for each month in the 20 month overlap period (Apr 1992Apr 1993 and Sep 1993-Mar 1994).

PAL $F_{\text {pre. }}$ Calculated globally (i.e., averaged over the whole continent), the difference between the average PAL and HRPT $F_{\text {pre }}$ in the overlap period was 0.016 fPAR units. However, when calculated regionally (i.e., averaged per IBRA region, which range between $4 \times 10^{3}$ and $419 \times 10^{3} \mathrm{~km}^{2}$ ), the differences varied between -0.026 and $0.133 \mathrm{fPAR}$ units. To minimise any remaining differences between the two datasets, the difference between the two averages for the overlap period was calculated for every PAL-equivalent pixel in the image extent (i.e., PAL $F_{\text {pre }}$-HRPT $F_{\text {pre }}$ ). These 'offset' values were then subtracted from the PAL $F_{\text {pre }}$ on a per-pixel basis, giving the final fPAR $(F)$ :

for PAL data, $\quad F=F_{\text {pre }}-$ offset

for HRPT data, $F=F_{\text {pre }}$.

\section{Results}

\subsection{Original NDVI}

The original, Australian-average monthly NDVI $\left(V_{\text {orig }}\right)$ calculated from the original reflectance data for both datasets is shown in Fig. 5a.
There are no obvious satellite-specific characteristics evident in the PAL $V_{\text {orig }}$ time-series. According to Kaufmann et al. (2000), the corrections applied to the PAL data have removed enough of the sensor calibration variability that NDVI calculated from these data can be used for long-term time-series analyses. In contrast to this, there are satellite-specific characteristics present in the HRPT time-series, with NOAA14 $V_{\text {orig }}$ being slightly higher than that from NOAA11 or NOAA16. This indicates that further sensor calibrations are required prior to time-series analyses using HRPT $V_{\text {orig. }}$. Comparison between the datasets shows that the PAL $V_{\text {orig }}$ is higher on average than that from HRPT and has larger seasonal amplitudes (Table 3). The root mean square difference (RMSD) between the two time-series' in the overlap period is $0.103 \mathrm{NDVI}$ units (or 0.098 in fPAR-equivalent units). These distinct characteristics stem from the different data specifications and processing histories of the two datasets (Table 2). In their original form, it is clear that the PAL and HRPT $V_{\text {orig }}$ are not equivalent representations of vegetation cover and are unsuitable as co-inputs to long-term time-series analyses.

\subsection{Soil-line variability}

The soil-line slope $\left(\alpha_{\mathrm{s}}\right)$ and intercept $\left(\beta_{\mathrm{s}}\right)$ determined for each month of the AVHRR time-series is presented in Fig. 6. For nearly every month, $\alpha_{\mathrm{s}}$ is less than 1 and $\beta_{\mathrm{s}}$ is between 0 and 4 , indicating that the observed soil line is typically being rotated clockwise, with most movement occurring over bright targets. Fig. 6 also shows distinct differences in the soil-line metrics between the PAL and HRPT data, again demonstrating the inherent differences between the two datasets. Of particular interest is the contrast in the internal patterns. The PAL slopes and intercepts form a generally seamless time-series across three satellites whereas the HRPT data contain an abrupt change between the slopes of NOAA14 and 16 .

The seasonality in $\alpha_{\mathrm{s}}$ and $\beta_{\mathrm{s}}$ indicates that the causes of this variability are also seasonal, which points towards atmospheric effects and/or SZA effects. According to Tanre et al. (1992) and Kaufman (1989), water-vapour absorption effects are likely to be the most significant atmospheric variables over sparsely vegetated surfaces. Considering neither dataset had water-vapour corrections applied, that atmospheric water-vapour content is highly seasonal and decreases measured $\rho_{\mathrm{N}}$, and that much of Australia is sparsely vegetated, water-vapour absorption is a possible cause of the variability in the soil line in the original reflectance data.
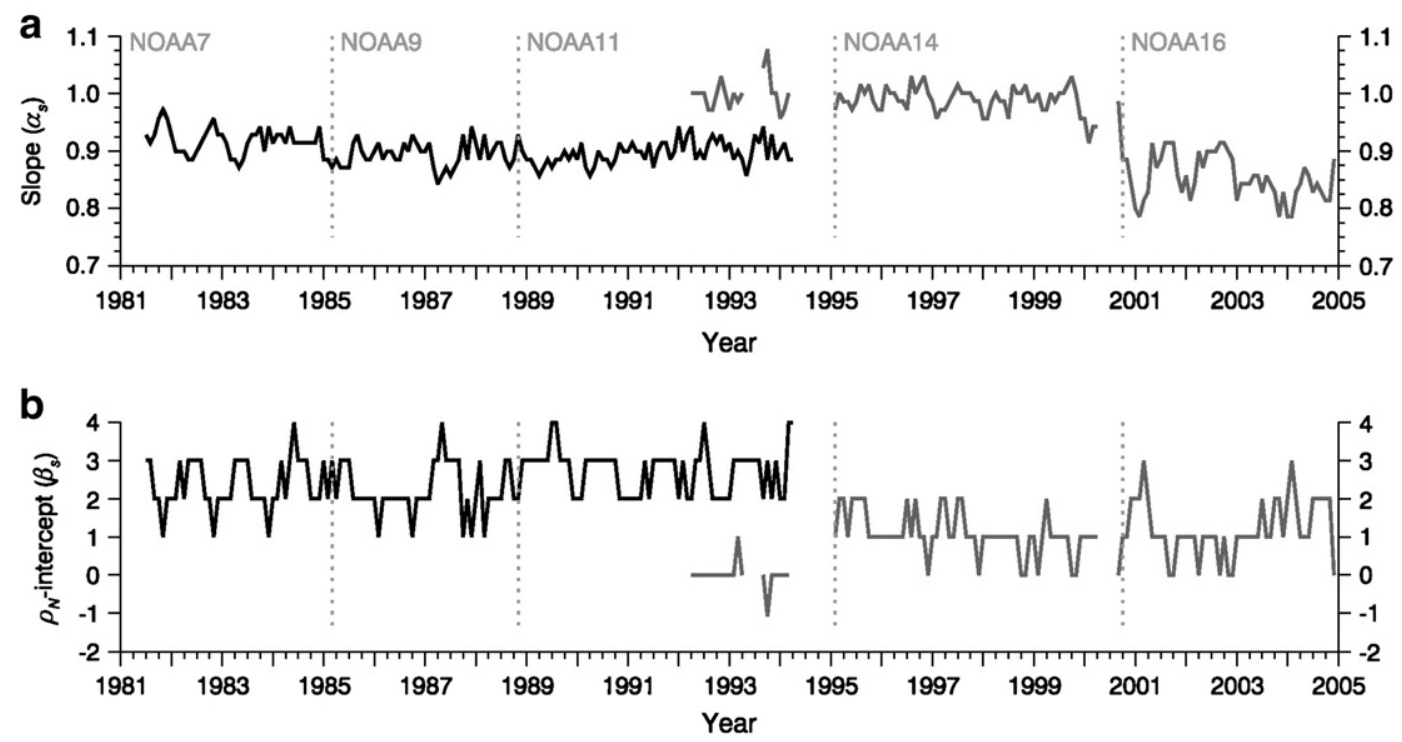

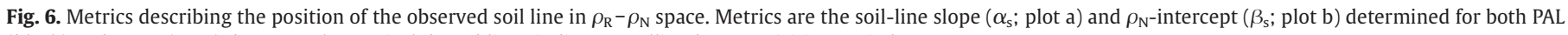
(black) and HRPT (grey) datasets. The vertical dotted lines indicate satellite data acquisition periods. 


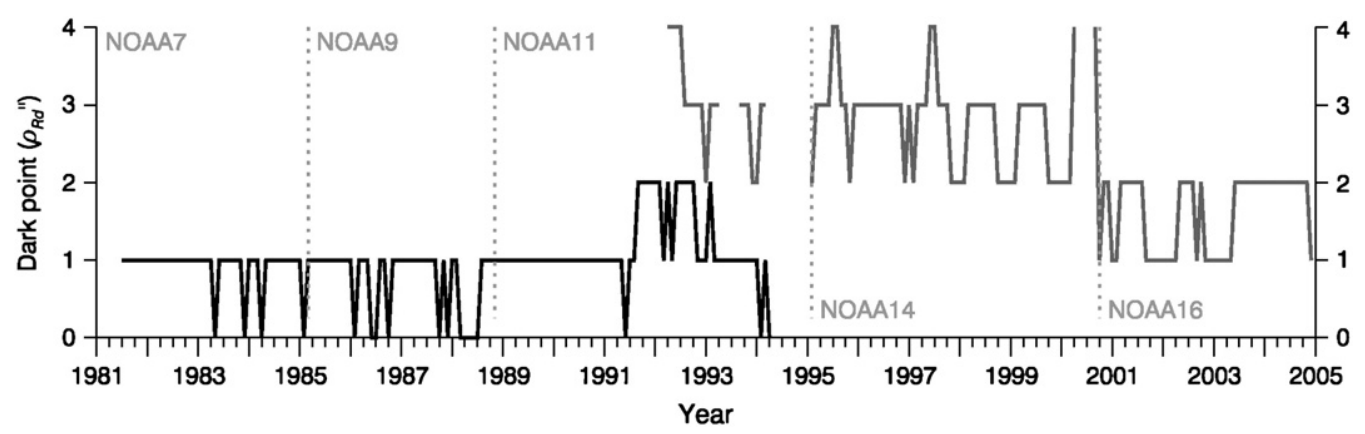

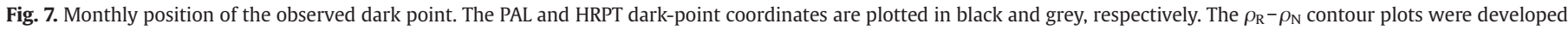

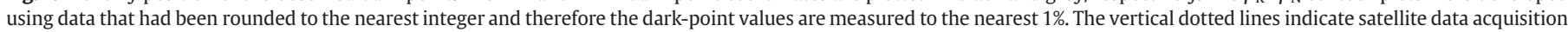
periods.

The satellite-specific characteristics in $\alpha_{\mathrm{s}}$ and $\beta_{\mathrm{s}}$ also suggest that some of the variability in the soil-line position is due to the effectiveness of post-launch calibrations. Both Kaufmann et al. (2000) and Tanre et al. (1992) report that the PAL calibrations are accurate and this is confirmed-in a relative sense-in Fig. 6. In contrast, the calibrations applied to the HRPT data have not been as effective and form one source of variability in the soil line that is addressed by this calibration methodology. The effect on the NDVI of removing soil-line variability from the reflectance data can be seen in Fig. 5b. The differences between the two datasets have been reduced and most of the satellitespecific differences within the HRPT $V_{\text {adj }}$ have been removed.

\subsection{Dark-point variability}

There is a strong contrast in the dark-point location between the PAL and the HRPT data (Fig. 7). Corrections for molecular scattering generally decrease measured $\rho_{R}$ (O'Brien et al., 2000) and those applied to the PAL data have produced a low and almost stationary dark point, located generally at $1 \% \rho_{\mathrm{R}}{ }^{\prime \prime}$. The HRPT data have not been corrected for molecular scattering (Table 2) and consequently the dark point is high and quite variable, containing a strong seasonal pattern. This variability appears to be due to molecular scattering, which increase measured $\rho_{\mathrm{R}}$ over densely vegetated targets. The spike between 1991 and 1993 coincides with the Mount Pinatubo eruption (Robock, 2000) which suggests that the dark-point corrections are capturing some of the effects of tropospheric aerosol scattering. The HRPT dark-point values (Fig. 7) have satellite-specific characteristics stemming from the interplay between atmospheric and sensor calibration effects (Kaufmann et al., 2000).

An implication of the sensitivity of the NDVI to variations in reflectances (O'Brien et al., 2000, Roderick et al., 1996a) is that the closer the cover triangle is to the origin, the more NDVI isolines are traversed by any given fluctuation in reflectance (Fig. 1) and the greater the resulting variability in the NDVI. As the $\rho_{\mathrm{Rd}}{ }^{\prime \prime}$ values for the PAL and the NOAA16 HRPT data are generally less than $2 \%$, removal of dark-point variability from these data has effectively moved the cover triangle further away from the origin. This should have not only lowered $V_{\text {cor }}$ relative to $V_{\text {adj }}$ but also dampened the amplitude of the seasonal pattern in $V_{\text {cor }}$. Although subtle, these effects are present in Fig. 5c. Conversely, $\rho_{\mathrm{Rd}}$ " values of the NOAA11 and 14 HRPT data were already close to $2 \%$ and there is little discernable difference between $V_{\text {adj }}$ and $V_{\text {cor }}$ values for these datasets at this continent-wide scale. The dark-point corrections have brought the two datasets further into agreement in the overlap period.

\subsection{Conversion of NDVI to fPAR}

The main effect of the conversion of $V_{\text {cor }}$ to $F_{\text {pre }}$ has been to amplify the seasonal variation in the signal (Fig. $5 \mathrm{~d}$ ). The calculated minimum and maximum NDVI thresholds, $V_{x}$ and $V_{n}$, were 0.67 and 0.09 for the
PAL data and 0.64 and 0.09 for the HRPT, respectively. The technique of converting $V_{\text {cor }}$ to $F_{\text {pre }}$ rescales each dataset between two absolute and biologically meaningful thresholds and thereby standardises the data range of the two datasets. As such, this is an important step in the overall calibration methodology.

The calculated offset values (Fig. 8) indicate that differences still exist between the two datasets. That such differences remain means this methodology does not fully account for all non-target signal variability within the data and/or that there remain inherent differences between the two datasets unrelated to atmospheric conditions and calibration variability. The geographic patterns in the offset values generally match patterns of landscape complexity (heterogeneity of surface cover). One possible reason for this is that the combination of imprecise geolocation and the MVC procedure biases NDVI values over complex landscapes (Holben, 1986, Tan et al., 2006). As the PAL data were created using the GAC sub-sampling procedure (Cracknell, 1997), this bias is more pronounced in the PAL data.

The geolocation of the HRPT imagery used here is precise to within half a pixel (E. King, pers. comm.). Even this level of precision causes any given pixel to 'wander' around its true location in the landscape. If that pixel wanders over an area with relatively high NDVI then, when MVC is applied, the high NDVI value is preferentially selected as the composited value. Consequently, over boundaries between high and low NDVI targets, high NDVI values effectively spread out into the adjacent low

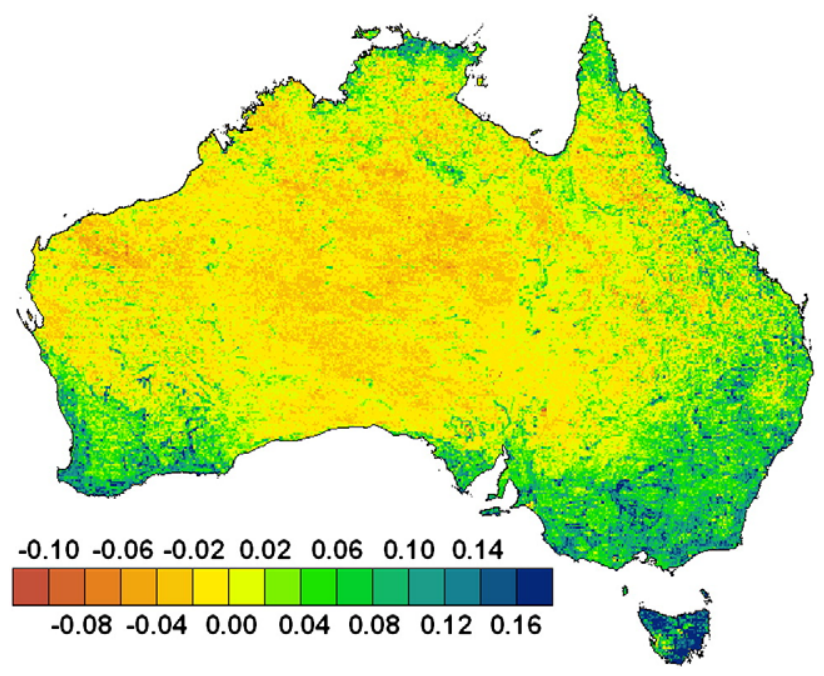

Fig. 8. The average difference in the overlap period between preliminary fPAR calculated from the PAL and HRPT datasets. The period of overlap is Apr 1992-Apr 1993 and Sep 1993-Mar 1994. The difference is calculated as PAL $F_{\text {pre }}-$ HRPT $F_{\text {pre }}$ and is calculated for every $0.08^{\circ}$ pixel. The 0 th, 5 th, 95 th, and 100 th percentiles were $-0.400,-0.030,0.112$ and 0.563 , respectively. Values are in units of fPAR. 

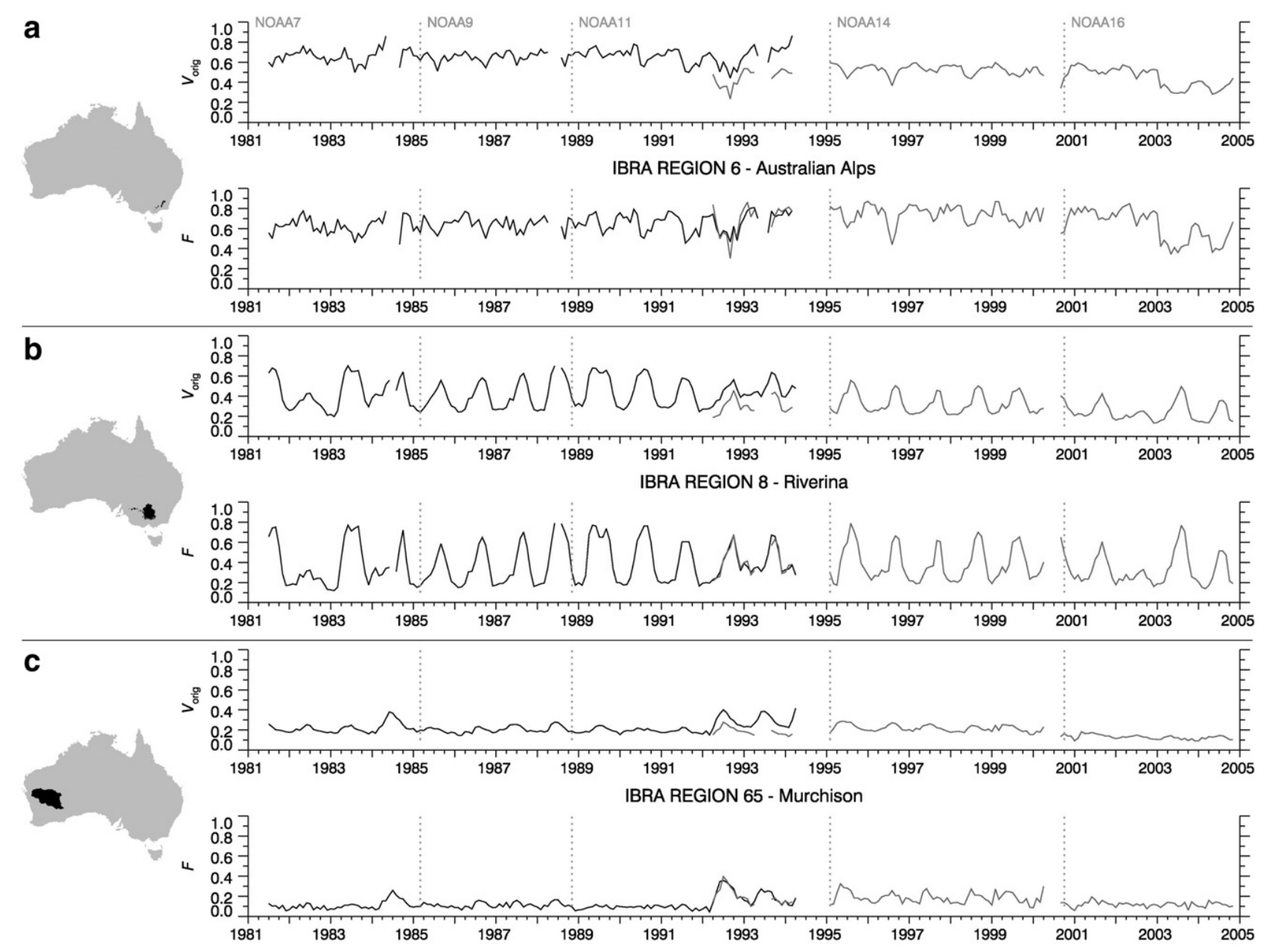

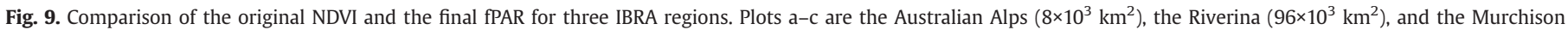

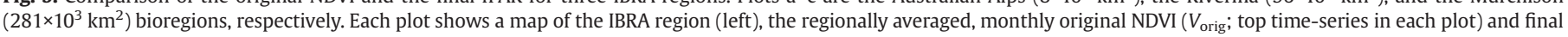
fPAR ( $F$; bottom time-series in each) for both PAL (black line) and HRPT (grey line) data. The grey dotted lines indicate satellite data acquisition periods.

NDVI areas (Holben, 1986). In GAC-sub-sampled data, the average of four HRPT pixels ( $\sim \mathrm{km}^{2}$ each) is used to represent the value of one GAC pixel $\left(\sim 16 \mathrm{~km}^{2}\right)$. Even slight wanderings in the four-pixel averages caused by geolocation errors can alter the value of entire GAC cells. Further, resampling of the averaged HRPT values to the GAC grid can exacerbate the wandering effect of the original HRPT cells (King, 2003). This means that the effective spatial footprint of a high-low NDVI boundary is greater in GAC imagery than in the original HRPT imagery. The overall effect is that, with typical geolocation errors, maximum-value-composited PAL NDVI will tend to be higher than the equivalent HRPT NDVI over landscapes containing discontinuities between dense and sparse (or no) vegetation.

After the offset was applied, the final Australian-averaged fPAR $(F)$ show extremely good agreement between the PAL and HRPT datasets (Fig. 5e and Table 3). The overall means and seasonal amplitudes are comparable and the RMSD in the overlap period is 0.027 fPAR unitsan improvement from the original 0.098-a difference which is now only slightly greater than the best possible precision of AVHRRderived NDVI (Roderick et al., 1996a), which is approximately 0.02 . This is a pleasing result considering the inherent differences in the original data specifications (Table 2). There are no longer obvious differences between the two datasets nor between satellite periods within either dataset. The same conclusions are made when examining results at regional scales (Fig. 9) meaning that, even though the method requires the analysis area to be large enough to encompass the full range of soil types, the final fPAR can be applied at both small and large scales. It can be seen from Fig. 9 that the methodology is effective in regions with high vegetation cover (Fig. 9a), with strong seasonal cycles in cover (Fig. 9b), and with low and sporadic vegetation cover (Fig. 9c). The effects of vegetation disturbance (e.g., the widespread fires of January 2003 in southeast Australia; Fig. 9a) and of climate variability (e.g., the El Niño-related droughts of 1982/83 and 2002/03 in eastern Australia; Fig. 9b) are preserved in the final fPAR data. The invariant-cover-triangle method has produced, from two distinct datasets, one essentially equivalent dataset suitable for use as a single input in long-term time-series analyses of vegetation.

\section{Discussion and conclusion}

We demonstrated the invariant-cover-triangle calibration method using, as a case study, two distinct AVHRR datasets. Results indicate that the methodology is robust and effective when applied to AVHRR data that have had different degrees of corrections applied-that is, atmospheric corrections and sensor calibrations. We expect the methodology to be applicable to red-NIR reflectance data acquired from any one sensor, regardless of which corrections have been applied, whether none, partial, or full atmospheric corrections, and regardless of the accuracy of post-launch calibrations. However, due to the variance in spectral bandwidths of different sensors, this method cannot be expected to effectively harmonise red-NIR reflectances acquired from different sensors, unless a spectral translation is performed (e.g., Yoshioka et al., 2003) prior to the invariant-cover-triangle calibration. 
The advantage of the approach we have outlined in this paper is that data with distinctly different correction histories can be rendered approximately equivalent and combined for the purposes of longterm time-series analyses.

One of the assumptions within this calibration methodology is that two features of the cover triangle-the soil line and the dark point-are temporally invariant in red-NIR reflectance space. Enforcing this stationarity therefore assumes an absence of trends in the spectral properties of bare soils and of dark, dense foliage across the study area (note that this is different from assuming the reflectance from these targets is constant). The difference between these assumptions in this invariant-cover-triangle approach and those inherent within traditional invariant-target approaches is significant. In the latter, reflectance from specific geographic targets and land-cover types are assumed constant whereas in the former all geographic locations and cover types are free from this constraint. In fact, the calibrated Australian AVHRR data used as a case study in this paper indicate that deserts and rainforests (which are commonly used invariant geographic targets) have all generally experienced long-term changes in fPAR over the analysis period (Donohue et al., 2007b; Schmidt et al. (2008) report similar results). The freedom of the cover-triangle approach from assumptions about ground target stability is a significant advantage when analysing long-term vegetation changes.

The invariant cover-triangle methodology performs a relative calibration and is designed to produce consistent, long-term vegetation information. It was not designed as a correction procedure per se and so doesn't quantify, or remove in an absolute sense, non-target signal variability. We haven't performed an assessment of the method's effectiveness in correcting for these uncertainties (as it is outside the scope of this paper) and we can only speculate about which are being removed. The methodology takes a 'lumped' approach, in that it removes the continentally averaged effects of scattering and absorption and of viewing angle variations. As such, it doesn't address the spatial variability in these effects. The results indicate that intersensor calibration discrepancies have been removed (Figs. 6 and 7). It seems reasonable, then, that sensor drift effects should also have been removed, although there is limited evidence of time-dependent trends in the soil-line and dark-point metrics (Figs. 6 and 7). We are confident that the dark-point corrections mimic Rayleigh corrections and are therefore removing much of the effect of molecular scattering (Fig. 7). The results suggest that the dark-point corrections are also removing some of the tropospheric aerosol scattering effects (Fig. 7) although evidence for this is less convincing. Finally, it is difficult to make conclusions from the results about the effectiveness of these corrections in removing water-vapour absorption, aerosol scattering, and viewing angle effects. Regardless, this technique has value because it uses two absolute and biologically meaningful reflectance features to remove the temporal effects of observation errors evident between each sensor in the time-series.

The example presented here used continental Australia as the study area, which spans $45^{\circ}$ of longitude $\left(110^{\circ} \mathrm{E}\right.$ to $\left.155^{\circ} \mathrm{E}\right)$ and $35^{\circ}$ latitude $\left(10^{\circ} \mathrm{S}\right.$ to $\left.45^{\circ} \mathrm{S}\right)$. We expect the invariant-cover-triangle method to be applicable to any study area that encompasses a sufficiently wide range of (unvegetated) soil types and that contains sufficient dark, dense vegetation cover so that both the soil line and dark point are identifiable in each image of the time-series. How large a study area must be to include these features depends on the spatial resolution of the sensor, the heterogeneity of cover types, and the range in the timing of growing seasons of vegetation within the imagery. In the absence of dry salt lakes within a study area, some other surface feature that is bright, spectrally invariant and which reflects approximately equal proportions of $\rho_{\mathrm{R}}$ and $\rho_{\mathrm{N}}$ (such as snow or water glint or perhaps concrete) must be present so that the soil line can be anchored consistently through time. The 20-pixel contour line chosen here to anchor the dark end of the soil line may not be the appropriate contour to use in other areas; an alternative region-specific value should be identified in each study.
Setting $M$ as $2 \%$ should be widely applicable, however the soil-line and dark-point metrics are specific to each case study.

The invariant-cover-triangle method lends itself to use in operational environments as it is simple, quick to implement (only requiring that an operator select the soil line and dark point), and does not require additional measured or modelled input data. The methodology can be further developed to be automatically implemented if the tasks of identifying the soil line and the dark point are automated, taking a similar approach to that of Fox et al. (2004). If AVHRR composite reflectance data are available in near-real-time, the invariantcover-triangle methodology can be used for real-time applications since each new dataset can be immediately processed without the need for re-processing of the entire time-series or the need to wait for the publication of post-launch calibration coefficients.

\section{Acknowledgements}

We would like to thank Dr E. King (CSIRO Marine and Atmospheric Research) for providing us with the AVHRR data and metadata, T. Van Niel and Dr J.P. Guerschman (both from CSIRO Land and Water) and four anonymous reviewers for their many helpful comments that improved earlier drafts of this paper. IDL code of the invariant-covertriangle methodology is available from the lead author, and the calibrated monthly Australian fPAR data are available at http://wwwdata.wron.csiro.au/rs/avhrr_fpar.

\section{References}

Asrar, G., Fuchs, M., Kanemasu, E. T., \& Hatfield, J. L. (1984). Estimating absorbed photosynthetic radiation and leaf-area index from spectral reflectance in wheat. Agronomy Journal, 76, 300-306.

Bacour, C., Breon, F. M., \& Maignan, F. (2006). Normalization of the directional effects in NOAA-AVHRR reflectance measurements for an improved monitoring of vegetation cycles. Remote Sensing Environment, 102, 402-413.

Baret, F., \& Guyot, G. (1991). Potentials and limits of vegetation indexes for LAI and APAR assessment. Remote Sensing Environment, 35, 161-173.

Baret, F., Guyot, G., \& Major, D. J. (1989). Crop biomass evaluation using radiometric measurements. Photogrammetria, 43, 241-256.

Berry, S. L., \& Roderick, M. L. (2002). Estimating mixtures of leaf functional types using continental-scale satellite and climatic data. Global Ecology and Biogeography, 11, 23-39.

Boer, M. M., \& Puigdefabregas, J. (2003). Predicting potential vegetation index values as a reference for the assessment and monitoring of dryland condition. International Journal of Remote Sensing, 24, 1135-1141.

Carlson, T. (2007). An overview of the "triangle method" for estimating surface evapotranspiration and soil moisture from satellite imagery. SENSORS, 7, 1612-1629.

Carlson, T. N., \& Ripley, D. A. (1997). On the relation between NDVI, fractional vegetation cover, and leaf area index. Remote Sensing Environment, 62, 241-252.

Che, N., \& Price, J. C. (1992). Survey of radiometric calibration results and methods for visible and near-infrared channels of NOAA-7, NOAA-9, and NOAA-11 AVHRRs. Remote Sensing Environment, 41, 19-27.

Cihlar, J., Ly, H., Li, Z. Q., Chen, J., Pokrant, H., \& Huang, F. T. (1997). Multitemporal, multichannel AVHRR data sets for land biosphere studies-artefacts and corrections. Remote Sensing Environment, 60, 35-57.

Cracknell, A. P. (1997). The Advanced Very High Resolution Radiometer. London: Taylor and Francis.

DeFries, R., Hansen, M., \& Townshend, J. (1995). Global discrimination of land cover types from metrics derived from AVHRR pathfinder data. Remote Sensing Environment, 54, 209-222.

Donohue, R. J., Roderick, M. L., \& McVicar, T. R. (2007a). On the importance of including vegetation dynamics in Budyko's hydrological model. Hydrology and Earth System Sciences, 11, 983-995.

Donohue, R. J., Roderick, M. L., \& McVicar, T. R. (2007b). Correcting long-term AVHRR reflectance data using the vegetation cover triangle. CSIRO Land and Water Science Report 26/07. Canberra: CSIRO Land and Water http://www.clw.csiro.au/publications/ science/2007/sr26-07.pdf

El Saleous, N. Z., Vermote, E. F., Justice, C. O., Townshend, J. R. G., Tucker, C. J., \& Goward, S. N. (2000). Improvements in the global biospheric record from the Advanced Very High Resolution Radiometer (AVHRR). International Journal of Remote Sensing, 21, 1251-1277.

Environment Australia (2000). Revision of the Interim Biogeographic Regionalisation for Australia (IBRA) and development of version 5.1. Canberra: Environment Australia.

Fox, G. A., Sabbagh, G. J., Searcy, S. W., \& Yang, C. (2004). An automated soil line identification routine for remotely sensed images. Soil Science Society of America Journal, 68, 1326-1331.

Galvao, L. S., Vitorello, I., \& Almeida, R. (1999). Effects of band positioning and bandwidth on NDVI measurements of tropical savannas. Remote Sensing Environment, 67 181-193. 
Gillies, R. R., \& Carlson, T. N. (1995). Thermal remote-sensing of surface soil-water content with partial vegetation cover for incorporation into climate-models. Journal of Applied Meteorology, 34, 745-756.

Gordon, H. R., Brown, J. W., \& Evans, R. H. (1988). Exact Rayleigh-scattering calculations for use with the Nimbus-7 Coastal Zone Color Scanner. Applied Optics, 27, 862-871.

Gould, W. (2000). Remote sensing of vegetation, plant species richness, and regional biodiversity hotspots. Ecological Applications, 10, 1861-1870.

Graetz, R. D., \& Gentle, M. R. (1982). The relationships between reflectance in the Landsat wavebands and the composition of an Australian semi-arid shrub rangeland. Photogrammetric Engineering \& Remote Sensing, 48, 1721-1730.

Graetz, R. D., Wilson, M. A., \& Campbell, S. K. (1995). Landcover disturbance over the Australian continent: A contemporary assessment. Biodiversity Series, Paper 7 Sport and Territories: Canberra: Department of Environment.

Guerschman, J. P., Paruelo, J. M., \& Burke, I. C. (2003). Land use impacts on the Normalized Difference Vegetation Index in temperate Argentina. Ecological Applications, 13, 616-628.

Gutman, G. G. (1999). On the use of long-term global data of land reflectances and vegetation indices derived from the Advanced Very High Resolution Radiometer Journal of Geophysical Research-Atmospheres, 104, 6241-6255.

Hall, F. G., Shimabukuro, Y. E., \& Huemmrich, K. F. (1995). Remote-sensing of forest biophysical structure using mixture decomposition and geometric reflectance models. Ecological Applications, 5, 993-1013.

Hill, M. J., Vickery, P. J., Furnival, E. P., \& Donald, G. E. (1999). Pasture land cover in eastern Australia from NOAA-AVHRR NDVI and classified Landsat TM. Remote Sensing Environment, 67, 32-50.

Holben, B. N. (1986). Characteristics of maximum-value composite images from temporal AVHRR data. International Journal of Remote Sensing, 7, 1417-1434.

Holm, A. M., Cridland, S. W., \& Roderick, M. L. (2003). The use of time-integrated NOAA NDVI data and rainfall to assess landscape degradation in the arid shrubland of Western Australia. Remote Sensing Environment, 85, 145-158.

Huete, A. R. (1988). A soil-adjusted vegetation index (SAVI). Remote Sensing Environment, 25, 295-309.

Hume, I. H., McVicar, T. R., \& Roderick, M. L. (2002). Optical properties of leaves in the visible and near-infrared under beam and diffuse radiance. Technical report 02/3. Cooperative Research Centre for Catchment Hydrology. http://www.catchment.crc. org.au/pdfs/technical200203.pdf

Jolly, W. M., Nemani, R., \& Running, S. W. (2005). A generalized, bioclimatic index to predict foliar phenology in response to climate. Global Change Biology,, 11, 619-632.

Jones, H. G. (1992). Plants and microclimate, Second Edn Cambridge: Cambridge University Press.

Kaufman, Y. J. (1989). The atmospheric effect on remote sensing and its correction. In G. Asrar (Ed.), Theory and applications of optical remote sensing (pp. 336-428). New York: John Wiley.

Kaufman, Y. J., \& Holben, B. N. (1993). Calibration of the AVHRR visible and near-IR bands by atmospheric scattering, ocean glint and desert reflection. International Journal of Remote Sensing, 14, 21-52.

Kaufman, Y. J. \& Tanre, D. (1992). Atmospherically Resistant Vegetation Index (ARVI) for EOS-MODIS. IEEE Transactions on Geoscience and Remote Sensing, 30, 261-270.

Kaufmann, R. K., Zhou, L. M., Knyazikhin, Y., Shabanov, N. V., Myneni, R. B., \& Tucker, C. J (2000). Effect of orbital drift and sensor changes on the time series of AVHRR vegetation index data. IEEE Transactions on Geoscience and Remote Sensing, 38, 2584-2597.

Kauth, R. J., \& Thomas, G. S. (1976). The tasselled cap - a graphic description of the spectral-temporal development of agricultural crops as seen by Landsat. Proceedings of the Symposium on Machine Processing of Remotely Sensed Data (pp. 44-51). West Lafayette: Purdue University.

Kidwell, K. B. (1998). NOAA Polar Orbiter data user's guide (TIROS-N, NOAA-6, NOAA-7, NOAA-8, NOAA-9, NOAA-10, NOAA-11, NOAA-12, NOAA-13 and NOAA-14). Suitland: National Environmental Satellite Data and Information Service, NOAA.

King, E. A. (2003). The Australian AVHRR data set at CSIRO/EOC: Origins, processes, holdings and prospects. CSIRO Earth Observation Centre Report 2003/04. Canberra: CSIRO Earth Observation Centre http://www.eoc.csiro.au/tech_reps/2003/tr2003 04.pdf

Los, S. O., North, P. R. J., Grey, W. M. F., \& Barnsley, M. J. (2005). A method to convert AVHRR Normalized Difference Vegetation Index time series to a standard viewing and illumination geometry. Remote Sensing Environment, 99, 400-411.

Lu, H., Raupach, M. R., McVicar, T. R., \& Barrett, D. J. (2003). Decomposition of vegetation cover into woody and herbaceous components using AVHRR NDVI time series. Remote Sensing Environment, 86, 1-18.

McVicar, T. R., \& Jupp, D. L. B. (1998). The current and potential operational uses of remote sensing to aid decisions on drought exceptional circumstances in Australia: A review. Agricultural Systems, 57, 399-468.

McVicar, T. R., Walker, J., Jupp, D. L. B., Pierce, L. L., Byrne, G. T. \& Dallwitz, R. (1996). Relating AVHRR vegetation indices to in situ measurements of leaf area index. Technical memorandum 96.5. Canberra: CSIRO Division of Water Resources http:/ www.clw.csiro.au/publications/technical96/DWR_TR96-05.pdf

Mitchell, R. M. (1999). Calibration status of the NOAA AVHRR solar reflectance channels: CalWatch revision 1. CSIRO Atmospheric Research Technical Paper No. 42. Aspendale: CSIRO Atmospheric Research http://www.cmar.csiro.au/e-print/open/mitchellr_1999a.pdf

Mitchell, R. M., O'Brien, D. M., Edwards, M., Elsum, C. C., \& Graetz, R. D. (1997). Selectio and initial characterisation of a bright calibration site in Strzelecki desert, South Australia. Canadian Journal of Remote Sensing, 23, 342-353.
Nemani, R. R., Keeling C. D., Hashimoto, H., Jolly W. M., Piper, S. C., Tucker, C. J., Myneni, R. B., \& Running, S. W. (2003). Climate-driven increases in global terrestrial net primary production from 1982 to 1999 . Science, 300, 1560-1563.

O'Brien, D. M., Dilley, A. C., \& Edwards, M. (2000). Interactions between surface and atmosphere in AVHRR shortwave channels. In T. R. McVicar (Ed.), Land EnvSat Workshop - 10th Australian Remote Sensing and Photogrammetry Conference (pp. 51-60). Adelaide: CSIRO Land and Water http://www.clw.csiro.au/publications/ technical2000/tr36-00.pdf

Oke, T. R. (1987). Boundary layer climates, Second Edn. London: Routledge.

Pickup, G., Chewings, V. H., \& Nelson, D. J. (1993). Estimating changes in vegetation cover over time in arid rangelands using Landsat MSS data. Remote Sensing Environment, 43, 243-263.

Pierce, L. L., Walker, J., Dowling, T. I., McVicar, T. R., Hatton, T. J., Running, S. W., \& Coughlan, J. C. (1993). Ecohydrological changes in the Murray-Darling Basin.3. A simulation of regional hydrological changes. Journal of Applied Ecology, 30, 283-294.

Price, J. C. (1991). Timing of NOAA afternoon passes. International Journal of Remote Sensing, 12, 193-198.

Price, J. C. (1987). Calibration of satellite radiometers and the comparison of vegetation indexes. Remote Sensing Environment, 21, 15-27.

Qi, J., Chehbouni, A., Huete, A. R., Kerr, Y. H., \& Sorooshian, S. (1994). A Modified Soil Adjusted Vegetation Index. Remote Sensing Environment, 48, 119-126.

Rao, C. R. N. (1993). Degradation of the visible and near-infrared channels of the Advanced Very High Resolution Radiometer on the NOAA-9 spacecraft: Assessment and recommendations for corrections. NOAA Technical Report NESDIS-70 Washington, D.C.: NOAA/NESDIS.

Richardson, A. J., \& Wiegand, C. L. (1977). Distinguishing vegetation from soil background information. Photogrammetric Engineering \&' Remote Sensing, 43, 1541-1552.

Robock, A. (2000). Volcanic eruptions and climate. Reviews of Geophysics, 38, 191-219.

Roderick, M., Smith, R., \& Cridland, S. (1996a). The precision of the NDVI derived from AVHRR observations. Remote Sensing Environment, 56, 57-65.

Roderick, M., Smith, R., \& Lodwick, G. (1996b). Calibrating long-term AVHRR-derived NDVI imagery. Remote Sensing Environment, 58, 1-12.

Roderick, M. L., Noble, I. R., \& Cridland, S. W. (1999). Estimating woody and herbaceous vegetation cover from time series satellite observations. Global Ecology and Biogeography, 8, 501-508.

Rondeaux, G., Steven, M., \& Baret, F. (1996). Optimization of soil-adjusted vegetation indices. Remote Sensing Environment, 55, 95-107.

Rouse, J. W., Haas, R. H., Schell, J. A., Deering, D. W., \& Harlan, J. C. (1974). Monitoring the vernal advancement and retrogradation (greenwave effect) of natural vegetation. NASA/GSFC Type III Final Report: Greenbelt.

Running, S. W., \& Nemani, R. R. (1988). Relating seasonal patterns of the AVHRR vegetation index to simulated photosynthesis and transpiration of forests in different climates. Remote Sensing Environment, 24, 347-367.

Schmidt, M., King, E. A., \& McVicar, T. R. (2008). A method for operational calibration of AVHRR reflective time series data. Remote Sensing of Environment, 112, 1117-1129.

Stowe, L. L., McClain, E. P., Carey, R., Pellegrino, P., Gutman, G., Davis, P., Long, C., \& Hart, S. (1991). Global distribution of cloud cover derived from NOAA/AVHRR operational satellite data. Advances in Space Research, 11, 51-54.

Szilagyi, J. (2000). Can a vegetation index derived from remote sensing be indicative of areal transpiration? Ecological Modelling, 127, 65-79.

Tan, B., Woodcock, C. E., Hu, J., Zhang, P., Ozdogan, M., Huang, D., Yang, W., Knyazikhin, Y., \& Myneni, R. B. (2006). The impact of gridding artifacts on the local spatial properties of MODIS data: Implications for validation, compositing, and band-toband registration across resolutions. Remote Sensing Environment, 105, 98-114.

Tanre, D., Holben, B. N., \& Kaufman, Y. J. (1992). Atmospheric correction algorithm for NOAA-AVHRR products - Theory and application. IEEE Transactions on Geoscience and Remote Sensing, 30, 231-248.

Tucker, C. J. (1979). Red and photographic infrared linear combinations for monitoring vegetation. Remote Sensing of Environment, 8, 127-150.

Vermote, E., \& Kaufman, Y. J. (1995). Absolute calibration of AVHRR visible and nearinfrared channels using ocean and cloud views. International Journal of Remote Sensing, 16, 2317-2340.

Walker, J., Jupp, D. L. B., Penridge, L. K., \& Tian, G. (1986). Interpretation of vegetation structure in Landsat MSS imagery - A case-study in disturbed semiarid Eucalypt woodlands. 1. Field data-analysis. Journal of Environmental Management, 23, 19-33.

Wellens, J. (1997). Rangeland vegetation dynamics and moisture availability in Tunisia: An investigation using satellite and meteorological data. Journal of Biogeography, $24,845-855$

Wolf, P. R. (1974). Elements of photogrammetry. Kogakusha: McGraw Hill.

Yoshioka, H., Miura, T., \& Huete, A. R. (2003). An isoline-based translation technique of spectral vegetation index using EO-1 Hyperion data. IEEE Transactions on Geoscience Remote Sensing, 41, 1363-1372.

Yoshioka, H., Miura, T., Huete, A. R., \& Ganapol, B. D. (2000). Analysis of vegetation isolines in red-NIR reflectance space. Remote Sensing Environment, 74, 313-332. 